\title{
An Investigation of the Relationship between L1 Lexical Translation Equivalence and L2 Vocabulary Acquisition
}

\author{
Ahmed Masrai $^{1} \&$ James Milton $^{1}$ \\ ${ }^{1}$ Department of Applied Language Studies, Swansea University, Swansea, UK \\ Correspondence: Ahmed Masrai, Department of Applied Language Studies, Swansea University, Swansea, SA2 \\ 8PP, UK. E-mail: a.m.masrai@swansea.ac.uk
}

Received: December 9, 2014 Accepted: January 4, 2015 Online Published: March 29, 2015

doi:10.5539/ijel.v5n2p1 URL: http://dx.doi.org/10.5539/ijel.v5n2p1

\begin{abstract}
Initial vocabulary acquisition is established through mapping second language (L2) word form to the existing first language (L1) meaning. However, although raised by some research, the effect of word translation equivalence on L2 vocabulary uptake is downplayed or disregarded. This study investigates the relationship between L1 lexical translation equivalence and L2 vocabulary acquisition in an experimental setting. A total of 156 native Arabic participants were given a vocabulary test in which they had to identify whether a word was known to them and then to supply the meaning of the word in their L1 and/or L2. The findings showed that L2 words with direct Arabic translation equivalents were significantly learned than words which do not. The study also indicated a smaller word frequency effect on learning words with non-direct L1 translation equivalents.
\end{abstract}

Keywords: mental lexicon, translation equivalence, vocabulary acquisition, word frequency, Arabic

\section{Introduction}

The literature on vocabulary acquisition considers command of an extensive vocabulary to be an indispensable condition for meaningful communication (Milton, 2009; Nation, 2001). However, developing a sizeable second language (L2) lexicon is, predictably, governed by several factors. Research into initial vocabulary learning, for example, has revealed that initial learning difficulty is influenced by how L2 words are pronounced (Rogers, 1969). Rogers' study suggested that words with non-English sound combinations and which were hard to pronounce were difficult to learn. Learners from Semitic languages, such as Arabic, for example, are inclined to focus on consonant letters in reading and accordingly find difficulty in other languages where vowels are essential. Other factors, such as abstractness (Higa, 1965), part of speech (Glanzer, 1962), the semantic relatedness of words in learning materials (Erten \& Tekin, 2008; Tinkham, 1993, 1997), frequency of first language (L1) translation equivalence and music during memorisation of L2 words (de Groot, 2006) and word frequency of occurrence (Kirkpatrick \& Curetin, 1949; Milton, 2009; Nation, 1990, 2001; Vermeer, 2001; Willis, 2001) were also found to contribute to the difficulty of L2 vocabulary learning.

Nonetheless, direct translation equivalents of the target words in the L2 with the native language of the learners might form another important factor affecting vocabulary acquisition. Words with direct translation equivalents are presumably learned more easily than words with non-direct translation equivalents.

In spite of the fact that the idea of direct translation equivalence might play a crucial role in L2 vocabulary acquisition, particularly with beginners, it remains underexplored. There are a few reported studies, however (e.g., Jiang, 2000, 2002, 2004), which have investigated the proposition that L2 lexical forms are frequently mapped to the existing semantic content of their L1 translation, instead of mapping them to entirely new semantic specifications of their own. Findings from these studies suggest strong support of the presence of L1 semantic content in L2 lexical entries. Jiang's studies have focused mainly on the processes of form-meaning mapping in the mental lexicon and the semantic transfer and development in L2 acquisition. In other words, Jiang examined the fact that a pair of semantically related words or synonyms in one language may have a single or different translation in another. The nature of the aims of his studies differs from the idea the current study is attempting to explore, in the sense that the current work focuses mainly on tackling the question of whether words with direct translation equivalents are potentially learned better than words with non-direct translation equivalents in the L1. However, conclusions from Jiang's work seem to suggest, with no claim, that the strong connections between L2 and L1 words facilitate L2 vocabulary learning. 
Research concerning English vocabulary learning in Saudi Arabia repeatedly suggests that school learners appear to face difficulty learning English as a Foreign Language (EFL) words. For example, Al-Hazemi (1993), Al-Bogami (1995) and Alsaif (2011) all suggest that Saudi students leave high school knowing an average of nearly 1,000 EFL words after around 832 hours of classroom instruction. This indicates that the rate of vocabulary uptake by Saudi school learners is about one word per contact hour. It is unquestionably a very low rate. Some factors, such as motivation, teaching methodology and input from textbooks, have been investigated without a clear explanation emerging.

The present study aims to explore empirically whether the connection between L1 Arabic, as a non-cognate language, and L2 English words, through word translation equivalents, have an impact on learning L2 vocabulary in an experimental setting. The assumption is that L2 words that have a direct translation equivalent are learned better than those that do not. The present study will also bring to the discussion the effect of word frequency on L2 vocabulary learning for the participants in this research. The study aims to achieve the following objectives:

1) To identify whether learners significantly tend to learn words which have direct translation equivalents or words which do not; or if translation equivalence has any effect on vocabulary learnability.

2) To establish whether a frequency effect makes a better contribution to word learnability than direct translation equivalence.

\section{Method}

\subsection{Participants}

The participants in this experiment were 156 male students who were randomly selected from two high schools in Saudi Arabia. All the participants were attending the final year of high school at the time of the data collection. The average age of the students in this study was 18 years old. The participants in this study should also have received, on average, 832 hours of EFL classroom input.

\subsection{Instrument}

A receptive vocabulary test was designed in order to collect data to answer the research questions. The test comprises 29 English lexical items. Fifteen items were selected to have direct translation equivalents in the learners' L1 (Arabic) and the remaining 14 words included in the test do not have direct translation equivalents. All the words presented in the test were chosen from the BNC (British National Corpus) lemmatised frequency list (Kilgarriff, 2006). All the lexical items included in the test were also cross-checked with the learners' textbooks to ensure that the learners had encountered them. According to Alsaif and Milton (2012), most new words in Saudi school textbooks are presented to learners before the secondary school level (Year 10). Participants in the current study, however, were all from year 12. Therefore, they were anticipated to have encountered all the test items.

The test designed in the present study was yes/no in nature; each learner was asked to identify whether he knew a word or not. Learners were also asked to provide a translation of the tested words in their L1 to eliminate the inclination to overestimate their vocabulary knowledge. It is noteworthy that the words included in the test were all selected from the same frequency bands. For example, the word snow, in the non-direct translation equivalent category, is ranked 2,627 in the frequency band and the word salt, in the equivalent category, is ranked 2,640. This criterion was followed with all the tested words. Moreover, part of speech and word length were also considered in order not to bias the word selection.

\subsection{Procedures}

The participants performed the task in a normal class setting. The time to complete the task was not restricted. However, the test was designed not to exceed 15 minutes to complete. In the written instructions given to the participants, they were asked to check the words they knew and to provide the L1 translation for them. The written instructions were given both in English and Arabic. The participants were also provided with the part of speech for each word. As the participants were from two different schools, volunteer teachers from each school administered the test after they had received aural and written instructions.

After the raw data were collected, they were marked manually to adjust the final score for each participant. As the words fall into two different categories, the score for each participant in each category was recorded. Finally, the total score for all the participants for each word was also recorded.

\section{Results}

The data in this study were analysed using SPSS software version 20. Firstly, the data were analysed to show the 
descriptive statistics for learners' scores in both direct and non-direct word translation equivalent types. Then, a paired sample test (t-test) was performed to compare mean scores for the learners for both types of words. The mean scores were also graphed to show clearly the difference between the means. The data were also analysed to examine the effect of word frequency on vocabulary learning when L2 words do not appear to have a direct translation equivalent in learners' L1 mental lexicon.

\subsection{Translation Equivalence Effect}

Results presented in Table 1 show the mean scores of learners' responses to the two types of words tested. The table also shows the minimum, maximum, standard deviation and standard deviation error. The mean score for learners' responses to the words which have a direct translation equivalent is 3.7308 (the maximum score is 15). In contrast, the mean score for learners' responses to the words with no direct translation equivalent is 0.6474 . It can be seen from the results that the standard deviation is higher than the mean score for the second pair (non-direct translation equivalent type of words). This could be attributed to the large variation recorded in learners' responses to the words with a non-direct translation equivalent. The minimum score recorded in this set of words was 0 and the highest was 7 , which was reached by only two participants.

Table 1. Descriptive statistics for learners' scores in equivalent and non-equivalent translation types of words

\begin{tabular}{lllllll}
\hline Word type & $N$ & Min. & Max. & $M$ & $S D$ & SD.EM \\
\hline Equivalent & 156 & 1 & 12 & 3.7308 & 2.32058 & 0.18580 \\
Non-equivalent & 156 & 0 & 7 & 0.6474 & 1.21711 & 0.09745 \\
Valid N (listwise) & 156 & & & & & \\
\hline
\end{tabular}

Note. $\mathrm{N}=$ number of participants; $\mathrm{Min}=$ minimum score; $\mathrm{Max}=$ maximum score; $\mathrm{M}=$ mean; $\mathrm{SD}=\mathrm{standard}$ deviation; $\mathrm{SD}$.EM $=$ standard deviation error of mean.

The mean scores were also graphed to illustrate the noticeable difference between means. Figure 1 shows that the mean scores for learners' responses to the words with a direct translation equivalent (grey column) is significantly higher than learners' responses to the words with a non-direct translation equivalent (white column).

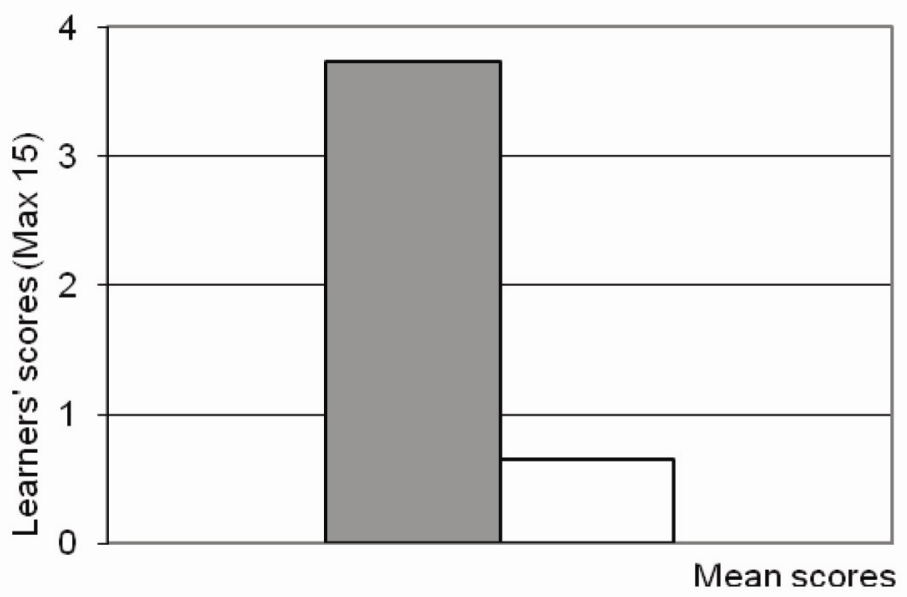

Figure 1. Illustration of mean scores for learners' responses to direct and non-direct translation equivalent words

The data reported in Table 1 suggest a relationship between word translation type and vocabulary uptake. However, further analysis of the data using paired sample statistics ( $t$-test) was performed. The results illustrated in Table 2 reveal that the difference between the mean scores for the two pairs of words investigated in the current study is statistically significant, $P>0.001$. The results suggest that learners tend to learn L2 words that have a direct translation equivalent in the learners' $L 1$ rather than those with a non-direct translation equivalent. 
Table 2. Paired sample test (t-scores) comparing the mean scores of L1 translationequivalent and non-direct translation equivalent

\begin{tabular}{|c|c|c|c|c|c|c|c|c|}
\hline & \multirow[b]{2}{*}{$M$} & \multirow[b]{2}{*}{$S D$} & \multirow[b]{2}{*}{$S D M E^{\dagger}$} & \multicolumn{2}{|c|}{$95 \% C I$} & \multirow[b]{2}{*}{$T$} & \multirow[b]{2}{*}{$D f$} & \multirow[b]{2}{*}{$P$} \\
\hline & & & & $L L$ & $U L$ & & & \\
\hline $\begin{array}{l}\text { Equivalent } \\
\text {-Non-equivalent }\end{array}$ & 3.0833 & 1.7037 & 0.1364 & 2.8139 & 3.3528 & 22.604 & 155 & 0.000 \\
\hline
\end{tabular}

Note. $\uparrow=$ Standard deviation of mean error; $\mathrm{CI}=$ confidence interval; $\mathrm{LL}=$ lower limit, $\mathrm{UL}=$ upper limit.

To consider the individual variation in learners' scores in the two types of words tested, the scores were presented in a scattergram. The scattergram shown in Figure 2 plots individual scores for the test for both sets of words. It can be seen that the overwhelming majority of these scores fall well above the diagonal line, confirming the individuals' tendency for the uptake of L2 vocabulary items that have direct translation equivalent over those which do not have this feature. Overall, the results presented in this section suggest that EFL learners can learn L2 lexical items with direct translation equivalents in their L1 much more easily than L2 words with non-direct translation equivalents.

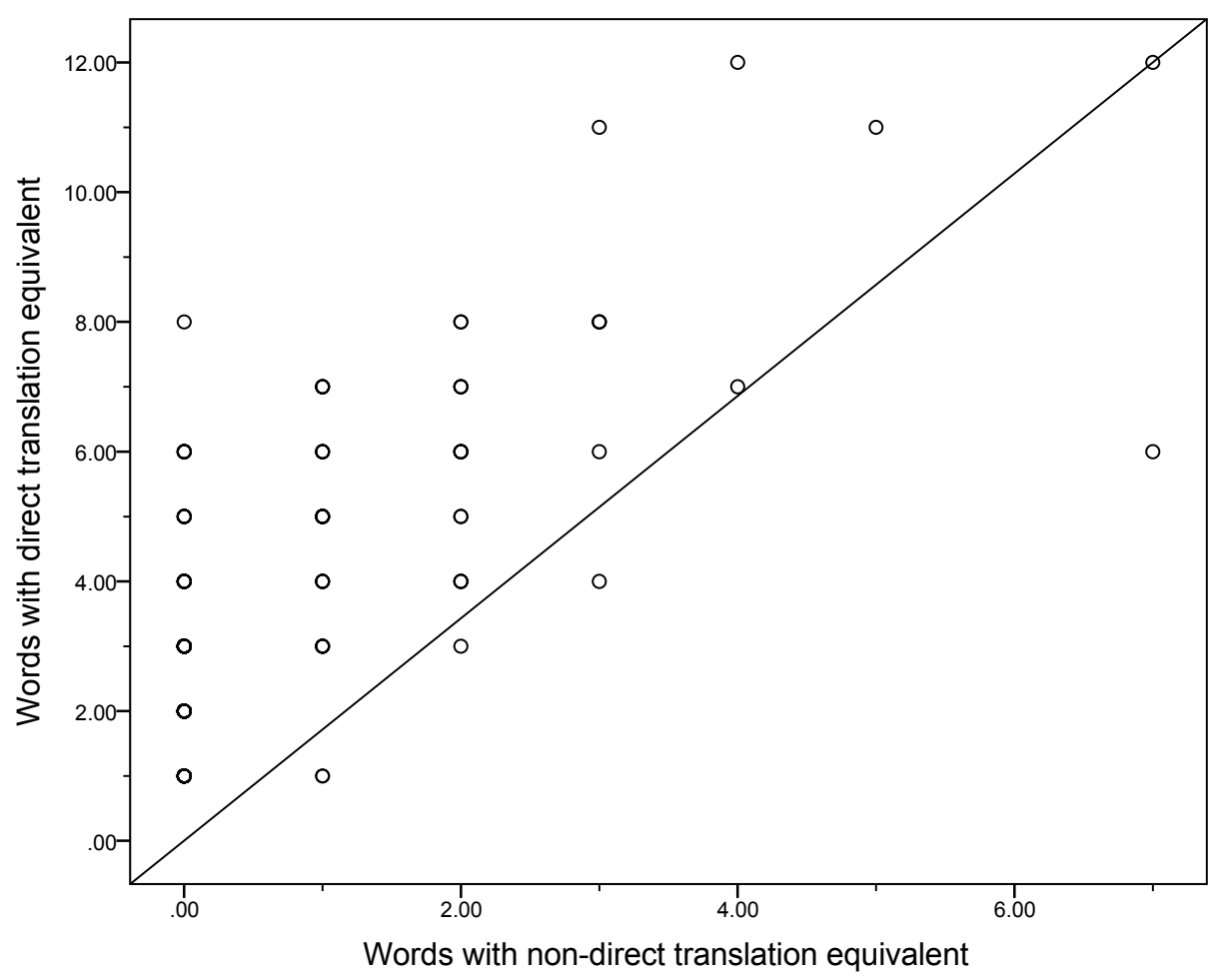

Figure 2. Scattergram of learners' scores in the test of words with and without direct L1 translation equivalents

\subsection{Word Frequency Effect}

It is generally assumed that there is a strong relationship between a word's frequency and the probability that a learner will encounter it and learn it (Milton, 2009). This assumption has been studied thoroughly by empirical work reported in Milton (2009). However, the frequency effect did not appear to be the most influential factor of vocabulary learning with the participants in this current study. It seems that learners here tend to lean heavily on word translation type in the first place and word frequency comes second.

The results presented in Table 3 below show that the learners appear to have difficulty learning words with a non-direct translation equivalent, although, in fact, they are at the same or higher word frequency level in English compared to the words with a direct translation equivalent. For example, the word test (v), which has a direct translation equivalent in the learners' L1, is ranked slightly lower than the word review (n), which is assumed not to have a direct translation equivalent. However, the word test was found to have been learned by 
142 participants, whereas the word review was found only to have been learned by six of those who participated.

This result does not undermine the importance of word frequency for learning L2 vocabulary, as it has been supported by a line of research. What also becomes apparent is that translation equivalents of L2 words in learners' L1 deserve attention in future research. However, because word frequency is acknowledged to be an influential factor in L2 vocabulary learning, further analysis was performed on the data to examine the frequency effect. The data were divided into two categories. The first category included the set of words with direct translation equivalents and the second words with a non-direct translation equivalent.

Pearson correlations, as presented in Table 4, suggest a positive and strong correlation $(r=0.657)$ between word frequency and vocabulary uptake of words that have a direct translation equivalent in learners' L1. In contrast, a negative correlation $(r=-0.063)$ was found between word frequency and vocabulary learning of words that do not have a direct translation equivalent in learners' L1. This result suggests that the frequency effect on vocabulary learning could be destabilised by other factors (e.g., words with a non-direct translation equivalent in the L1). Further discussion and the pedagogical implications relevant to this will be discussed later in the paper.

Table 3. Sample of words tested for frequency and word translation equivalence type

\begin{tabular}{lllll}
\hline Word & Occurrences in the BNC & $\begin{array}{l}\text { Resp. max } \\
(156)\end{array}$ & $\begin{array}{l}\text { Translation } \\
\text { equivalent }\end{array}$ & $\begin{array}{l}\text { Non-direct translation } \\
\text { equivalent }\end{array}$ \\
\hline test & 7868 & 142 & $\sqrt{ }$ & $\sqrt{ }$ \\
review & 7878 & 6 & $\sqrt{ }$ & $\sqrt{ }$ \\
patient & 23106 & 43 & $\sqrt{ }$ & $\sqrt{ }$ \\
at & 534162 & 2 & $\sqrt{ }$ \\
crazy & 3826 & 26 & $\sqrt{ }$ & $\sqrt{ }$ \\
charity & 4073 & 2 & & \\
salt & 3096 & 8 & & \\
snow & 3112 & & & \\
\hline
\end{tabular}

Table 4. Pearson correlations between frequency effect and words with a translation equivalent and non-direct translation equivalent

\begin{tabular}{|c|c|c|}
\hline & Translation equivalent & Non-direct translation equivalent \\
\hline Frequency effect & $0.657 * *$ & -0.063 \\
\hline
\end{tabular}

\section{Discussion}

The aims of the study presented in this chapter were to explore the relationship between word translation type and vocabulary learnability and to examine the effect of word frequency compared to word translation type on L2 vocabulary uptake. The quantitative data presented in the first part of the results section show a significant relationship between words with a direct translation equivalent and vocabulary learning. The learners were significantly found to uptake L2 words with a direct translation equivalent in their L1 rather than words which do not have a direct translation equivalent. This finding appears to support empirically Milton's (2009) assumption that L2 words with a translation equivalent in learners' L1 are probably learned much more easily than words with a non-direct translation equivalent.

The findings in this study might also be supported by studies of form-meaning mapping in second language vocabulary acquisition (e.g., Ausubel, 1964; Jiang, 2000, 2002). It is agreed by some scholars that one of the most essential tasks in acquiring L2 vocabulary is mapping lexical form to meaning. This could happen either by mapping new L2 words to meanings or concepts which have evolved in the process of L2 vocabulary acquisition, or to an existing semantic or conceptual system (Jiang, 2002). The first lexical mapping process, stated above, requires, however, a developed L2 mental lexicon. The second proposed mapping process, which is mapping new L2 lexical items to existing meanings and concepts, is probably what L2 beginners utilise when learning L2 vocabulary.

The learners who took part in this study are at a low level of English and have not yet achieved a developed L2 mental lexicon. They also mainly use school textbooks, which have been proved to be a poor input (Alsaif \& Milton, 2012), as the only source for learning L2 vocabulary. Therefore, creating new concepts for new L2 words will be a highly problematic task for them at their level, while assigning L2 lexical items to existing 
knowledge might be an easier task. This discussion might, to an extent, explain why Saudi school learners have been found to learn words which have direct translation equivalents rather than words which do not. Learners can link an L2 word to the meaning in their L1 when it has a direct equivalent, but they need further understanding of a word which does not have a direct meaning.

The second part of the results in this study deal with the effect of word frequency on L2 vocabulary uptake when considering a word translation type. It was found that even when a word appears more frequently in the non-direct translation equivalent set than a word in the direct translation equivalent set, there is difficulty in learning the former. According to Milton (2009), although it is evident how influential word frequency can be on vocabulary learning, there are factors associated with word difficulty and learning burden. These factors, such as the word translation type investigated in this study, could destabilise the frequency effect on L2 vocabulary learning.

Interestingly, the word frequency impact on L2 vocabulary learning was apparent when L2 words have a direct translation equivalent in the learners' L1. The correlation $(r=0.657)$ between word frequency effect and words with a translation equivalent was strong, which suggests the importance of word frequency in learning an L2. This kind of predictable relationship recommends further investigation of word translation equivalence along with other factors, such as word length, part of speech and repetition, combined in one model to mapL2 vocabulary learning difficulty.

It is worth mentioning, however, that the number of words examined in the current study is small. Therefore, if this study is to be replicated, it follows that this limitation should be taken into account. A larger number of words might help in generalising the findings more confidently. Nevertheless, the study suggests that EFL teachers should pay more attention to L2 words with non-direct translation equivalents in learners' L1 lexicons. They could provide learners with these kinds of words in appropriate contexts and introduce them in relevant activities. This should help learners to further understand these words and create applicable concepts for them in the $\mathrm{L} 2$.

\section{Conclusions}

At the outset of the current paper, it was mentioned that research in vocabulary learning in Saudi Arabia consistently reports low vocabulary uptake by Saudi school learners. Reasons why learners repeatedly score very low marks in vocabulary size tests remain unclear. Alsaif and Milton (2012), however, concluded that insufficient and inappropriate vocabulary presented in school learners' textbooks might explain one of the issues associated with students' vocabulary uptake.

Findings from this paper suggest that another issue pertaining to EFL vocabulary learning is L2 (English) words with a non-direct translation equivalent in learners' L1 (Arabic). Results appear to confirm that Saudi school learners, and this might be the case with native Arabic learners of English from different Arabic backgrounds, have a greater potential to learn words which have a direct translation equivalent in Arabic than words that do not have a direct translation equivalent. It is clear from the findings that words with a non-direct translation equivalent are difficult to learn, even when they are more frequent than those with a direct translation equivalent.

What has been found here seems to conform to findings from previous work. Coady, Magoto, Hubbard, Grane and Mokhtari (1993), for example, proposed that it was highly probable that EFL learners attach an L2 label to an existing native-language schema, rather than creating an entirely new one for frequently occurring universal concepts. In the early stages of L2 learning, learners do not appear to formulate a distinct conceptual structure, but tend to rely on L1 forms to access L2 lexical meaning. Thus, lexical items with a direct translation in L1 can benefit from lexical transfer, while, in contrast, semantic development is needed for L2 lexical items without an L1 translation equivalent to become part of L2 learners' acquired vocabulary.

\section{References}

Al-Bogami, A. (1995). Teaching English vocabulary to EFL male students at intermediate and secondary public schools in Riyadh. (Unpublished Masters dissertation). King Saud University, Riyadh.

Al-Hazemi, H. (1993). Low level EFL vocabulary tests for Arabic speakers. (Unpublished doctoral dissertation). University of Wales, Swansea.

Alsaif, A. (2011). Investigating vocabulary input and explaining vocabulary uptake among EFL learners in Saudi Arabia. (Unpublished doctoral dissertation). Swansea University.

Alsaif, A., \& Milton, J. (2012). Vocabulary input from school textbooks as a potential contributor to the small vocabulary uptake gained by English as a foreign language learners in Saudi Arabia. The Language 
Learning Journal, 40(1), 21-33. http://dx.doi.org/10.1080/09571736.2012.658221

Ausubel, D. P. (1964). Adults versus children in second-language learning: psychological considerations. The Modern Language Journal, 48(7), 420-424. http://dx.doi.org/10.1111/j.1540-4781.1964.tb04523.x

Coady, J., Magoto, J., Hubbard, P., Graney, J., \& Mokhtari, K. (1993). High frequency vocabulary and reading proficiency in ESL readers. In T. Huckin, M. Haynes \& J. Coady (Eds.), Second language reading and vocabulary learning (pp. 217-228). Norwood, NJ: Ablex.

De Groot, A. M. B. (2006). Effects of stimulus characteristics and background music on foreign language vocabulary learning and forgetting. Language Learning, 56(3), 463-506. http://dx.doi.org/10.1111/j.1467-9922.2006.00374.x

Erten, I. H., \& Tekin, M. (2008). Effects on vocabulary acquisition of presenting new words in semantic sets versus semantically unrelated sets. System, 36(3), 407-422. http://dx.doi.org/10.1016/j.system.2008.02.005

Glanzer, M. (1962). Grammatical category: a rote learning and word association analysis. Journal of Verbal Learning and Verbal Behavior, 1(1), 31-41. http://dx.doi.org/10.1016/S0022-5371(62)80016-4

Higa, M. (1965). The psycholinguistic concept of "difficulty" and the teaching of foreign language vocabulary. Language Learning, 15(3-4), 167-179. http://dx.doi.org/10.1111/j.1467-1770.1965.tb00799.x

Jiang, N. (2000). Lexical representation and development in a second language. Applied Linguistics, 21(1), 47-77. http://dx.doi.org/10.1093/applin/21.1.47

Jiang, N. (2002). Form-meaning mapping in vocabulary acquisition in a second language. Studies in Second Language Acquisition, 24(04), 617-637. http://dx.doi.org/10.1017/S0272263102004047

Jiang, N. (2004). Semantic transfer and its implications for vocabulary teaching in a second language. The Modern Language Journal, 88(3), 416-432. http://dx.doi.org/10.1111/j.0026-7902.2004.00238.x

Kilgarriff, A. (2006). BNC database and word frequency lists. Retrieved from http://www.kilgarriff.co.uk/bnc-readme.html - lemmatised

Kirkpatrick, J., \& Cureton, E. (1949). Vocabulary item difficulty and word frequency. Journal of Applied Psychology, 33(4), 347-351. http://dx.doi.org/10.1037/h0063369

Milton, J. (2009). Measuring second language vocabulary acquisition. Bristol: Multilingual Matters.

Nation, P. (1990). Teaching and learning vocabulary. New York: Heinle\&Heinle Publishers.

Nation, P. (2001). Learning vocabulary in another language. Cambridge: Cambridge University Press.

Rodgers, S. (1969). Measuring vocabulary difficulty: An analysis of item variables in learning Russian-English vocabulary pairs. International Review of Applied Linguistics in Language Teaching, 7, 327-343.

Tinkham, T. (1993). The effect of semantic clustering on the learning of second language vocabulary. System, 21(3), 371-380. http://dx.doi.org/10.1016/0346-251X(93)90027-E

Tinkham, T. (1997). The effects of semantic and thematic clustering on the learning of second language vocabulary. Second Language Research, 13(2), 138-163. http://dx.doi.org/10.1191/026765897672376469

Vermeer, A. (2001). Breadth and depth of vocabulary in relation to L1/L2 acquisition and frequency of input. Applied Psycholinguistics, 22, 217-234.

Willis, M. (2001). Lexico-syntactic development at intermediate/advanced levels. Paper presented at the BAAL Conference, Reading, UK.

\section{Copyright}

Copyright for this article is retained by the author(s), with first publication rights granted to the journal.

This is an open-access article distributed under the terms and conditions of the Creative Commons Attribution license (http://creativecommons.org/licenses/by/3.0/). 